\title{
Dossiê: A Pós-Graduação em Psicologia fora do eixo sul-sudeste: características e demandas
}

A Pós-graduação brasileira vem passando por uma das suas maiores crises. As ameaças se originam de diferentes fontes: ameaça de cortes de bolsas e de recursos, cancelamento de editais de fomento, diminuição de postos de trabalhos para recém-doutores e precarização dos contratos de trabalho já existentes. As ameaças às Ciências Humanas e Sociais são ainda mais agudas. Identificadas atualmente como áreas do conhecimento menos importantes e não prioritárias a atenção dada a este campo da ciência é ainda mais escassa. Foi neste contexto que a ideia deste número especial surgiu.

Atualmente, existem no Brasil mais de 400 cursos de graduação em psicologia e um pouco mais de 60 cursos de pós-graduação stricto sensu. Mais da metade desses cursos surgiram nos últimos 25 anos.

Existe uma grande concentração de cursos, tanto na graduação como na pós-graduação, na região Sudeste, seguida pelas regiões Nordeste, Sul, Centro-Oeste e por fim, a região Norte. No entanto, dentro de cada uma dessas regiões, há grandes disparidades. Por exemplo, quando pensamos no Sudeste, pensamos em São Paulo, Rio de Janeiro e Minas Gerais. Mas lá também tem o curso da UFES, com mais de 20 anos, mas cujos recursos disponibilizados pelo Estado brasileiro para seu funcionamento se igualam aos cursos do Nordeste. No Centro-Oeste, temos a UNB, que é a única que se iguala às instituições do Sudeste, no que se refere aos recursos recebidos. E por fim, a UFRGS aglutina praticamente mais da metade dos recursos destinados às instituições do Sul do Brasil.

Assim, este número especial se configurou como uma oportunidade para que pesquisadores ligados à cursos de Pós-graduação fora dos grandes e tradicionais centros de pesquisa mostrarem seu trabalho. Acredito que o resultado é profundamente estimulante, pois, em conjunto, os trabalhos ora publicados mostram cursos pulsantes, que lutam para sobreviver e conseguem resistir às dificuldades cotidianas.

Assim, abrimos esse número especial com o primeiro trabalho, intitulado "A pós-graduação brasileira: sua construção assimétrica e algumas tentativas de superação". Neste artigo os autores descrevem a origem e desenvolvimento do sistema de pós-graduação no Brasil, desde sua implementação na década de 1960 até os dias de hoje, demonstrando que apesar do aumento regular no número de Programas de Pós graduação (PPG) e da produção científica brasileira as assimetrias regionais se mantem ao longo da história.

Posteriormente, o segundo, intitulado "Periférico e comunitário: características e desafios de um programa de pós-graduação em Psicologia no Centro-Oeste", apresenta o impacto positivo dos investimentos em pesquisa na produção científica, identificando, também, os eixos temáticos das teses e dissertações produzidas pelos discentes. Os autores discutem a importância de políticas de apoio a produção científica e descentralização de recursos como forma de promover a ciência em todo o território brasileiro.

O terceiro trabalho, intitulado "O Programa de Pós-Graduação em Psicologia da Universidade Federal do Amazonas: Proposta e Perspectivas para a Região Amazônica", por sua vez, discute as dificuldades enfrentadas para a implantação e consolidação de pós-graduação em psicologia na região Amazônica. Nesta mesma linha, temos o quarto trabalho, intitulado "O ensino e a pesquisa no âmbito da Pós-Graduação em Psicologia da Universidade Federal do Piauí: desafios e dificuldades" relata a criação e a trajetória inicial do Programa de Pós-Graduação em Psicologia na UFPI, discutindo a importância da interiorização da pós-graduação no Brasil.

O quinto trabalho, "Problemáticas sociais e suas relações com a pesquisa e a extensão: contribuições do Programa de Pós-Graduação em Psicologia da UFC" mostra a articulação entre a prática de pesquisa com os desdobramentos advindos da extensão universitária, já que prioriza em sua política de produção de conhecimento a tematização de fenômenos sociais que se apresentam especialmente no contexto nordestino.

O sexto trabalho, intitulado "Desafios e Perspectivas de um Programa de Pós-Graduação em Psicologia de uma Instituição Privada no Nordeste brasileiro", amplia essa discussão mostrando a pluralidade teórica e metodológica que constitui o PPG-Psi da UNIFOR e aponta que os principais desafios dos docentes se referem ao imperativo econômico que rege as instituições de ensino superior privadas.

Em seguida, temos o sétimo trabalho, "Psicologia e políticas sociais: as contribuições de um programa de pós-graduação em Psicologia" realiza o caminho inverso do apresentado no segundo pois, ao invés de discutir o 
impacto de políticas públicas sobre a produção científica discute o impacto da produção científica sobre políticas públicas, tanto para sua avaliação como para sua implantação. Os autores destacam a importância da produção científica para a construção de políticas públicas mais sensíveis aos problemas sociais e, portanto, mais eficazes e eficientes para a população. Ressalta-se, assim, a importância da ciência na vida das pessoas e da sociedade.

O oitavo, "Avaliação Psicológica na pós-graduação: um panorama das regiões Centro-Oeste, Nordeste e Norte do Brasil", apresenta a caracterização atual sobre os dados de distribuição do ensino de Avaliação Psicológica no âmbito da Pós-graduação Stricto Sensu nas regiões Centro-Oeste, Nordeste e Norte do Brasil. Os resultados evidenciaram um aumento na quantidade de pós-graduados, em Programas de Pós-graduação Stricto Sensu e nos laboratórios de pesquisa, porém também ressalta as disparidades existentes entre as regiões sul-sudeste e demais regiões do Brasil.

O nono e décimo trabalhos apresentam os desafios das pesquisas experimentais em instituições fora do eixo Sul-Sudeste. Assim, temos o trabalho intitulado "Contribuições da Análise do Comportamento na Escola: experiências do Programa de Pós-Graduação Stricto Sensu em Psicologia da PUC Goiás", que discute a relevância dos estudos realizados nessa área para Goiânia e região, principalmente no que se refere ao ambiente escolar. Este artigo também apresenta a aplicação do conhecimento científico na comunidade e, de forma mais específica, na escola reforçando, uma vez mais, a importância da ciência na vida das pessoas e sociedade. Em seguida, temos o trabalho "Estudos Descritivos e Experimentais em Contextos Aplicados: Dados Científicos e Impacto Prático", que discute a aplicação dos conhecimentos científicos, mais especificamente os estudos realizados a partir da Análise do Comportamento, e mostra a concentração de estudos descritivos e/ou experimentais que abarcam diferentes aspectos do comportamento emitidos por pessoas diagnosticadas com algum transtorno mental, assim como por pessoas que não apresentam diagnóstico psiquiátrico. $O$ artigo apresenta uma importante reflexão acerca da relação entre comportamento e psicopatologia e convida ao leitor a reavaliar a naturalização dos critérios diagnósticos em psiquiatria.

Por fim, o décimo primeiro trabalho, "Psicodinâmica do trabalho: da França ao Estado Goiás: sua inserção na comunidade", descreve o percurso do desenvolvimento desta linha de pesquisa e discute a produção bibliográfica resultante de 20 anos de orientações de dissertações e tese.

Ana Raquel Rosas Torres

Universidade Federal da Paraíba

Estudos de Psicologia, 24(2), abril a junho de 2019, 101-102 